\title{
Passenger Service System
}

\author{
Minnuja Shelly ${ }^{1}$, Abhiram P. S ${ }^{2}$, Mohammed Aslam ${ }^{3}$, Sreebal Anil ${ }^{4}$ \\ Assistant Professor, Department of Computer Science, Universal Engineering College, Vallivattom, India ${ }^{1}$ \\ Student, Department of Computer Science, Universal Engineering College, Vallivattom, India ${ }^{2,3,4}$
}

\begin{abstract}
Increased competition in the commercial transportation industry has made service quality of every transportation agencies as one of the key competitive measures to attract passengers against their rivals. in- flight services ,particularly food delivery and waste collections, have a notable impact on perception of the overall airline's service quality because they are directly and in directly provided to passengers during flight. This is the scenario in every industry. This project consists of two sections, passenger section, they can request their needs by pressing a button in the keypad and it send to the control room section and it is displayed on an LCD control room section.: The requested needs may be food, water and if it is "any other help" the airhostess directly goes to the requested person
\end{abstract}

Keywords: Embedded System, Microcontroller, Data Modem

\section{INTRODUCTION}

Todays passenger service system is not giving more important to the service to the passengers and the service providence is more time consuming .if want to give service to multiple passengers they have to wait until the service request reaches to each passenger ,handicapped are not more satisfied by the service of service coordinator. Here we introduce a design of an passenger service system that is capable of service the passenger , all requirement are provided with out any time delay and give equal important to handicapped person

\section{RELATED WORKS}

In $^{[1]}$ The Internet of Things (IoT) based system is for catering passengers' services and requests in long journey railways. The system is to collect requests from passengers from each coach, track the location of crew members within train and allocate them requests from passengers. This allocation of the requests to the crew members takes place depending on the service arrival time, location information and workload factor of crew member. As proposed project is based on ICN architecture, it will use secure device discovery concept to make system more secure. The proposed system will provide quick service to passengers and also increase comfort in journey. Requests for the services from passengers are fairly distributed among the crew members available on board in railways Analysis can be done by comparing with current system.

$\mathrm{In}^{[2]}$ The present system needs much advancement in railway communication system in the area of journey reservation, catering, safety and rescue operations. It is pertinent to bring out here the present expectation of passenger should be of interactive mode and user friendly. This paper technically brings out a visible solution for modernizing the railway system. By listing the priorities it is seen that there is a need for display of seat layout for passenger selection during reservation. The present static reservation chart displayed on the train lacks updated information for the usage of enroute passengers. Also there is no facility for finding out details such as actual arrival and departure timing for onboard passengers, catering arrangements and rescue operations for intimation and immediate action.

$\mathrm{In}^{[3]}$ Wirelessly communicating embedded devices are brought to one another in a single link over Internet called IoT (Internet of Things). If all objects and people in daily life were equipped with identifiers, computers could manage and inventory them. Besides using RFID, the tagging of things may be achieved through such technologies as near field communication, barcodes, QR codes and digital watermarking. Here new method of using embedded technology to provide such application, Arduino is used as an embedded controller to interface Ethernet shield with a PC/Laptop to provide IoT over Ethernet. Whenever a user need to check the vehicle in the parking lot, uses the ID and password to logon into the airport web link and view the status of the car in the parking lot using IoT. IoT Based Airport Parking System is discussed here to implement Arduino environment as IoT application.

$\ln ^{[4]}$ The modifications made to a connected word speech recognition algorithm based on hidden Markov models (HMM's) which allow it to recognize words from a predefined vocabulary list spoken in an unconstrained fashion. The novelty of our approach is that we create statistical models of both the actual vocabulary words and the extraneous speech and background. An HMM-based connected word recognition system is then used to find the hest sequence of hack- ground, extraneous speech, and vocabulary word models for matching the actual input. Word recognition accuracy of $99.3 \%$ on purely iso- lated speech (i.e., only vocabulary items and background noise were present), and 
95.1\% when the vocabulary word was embedded in un- constrained extraneous speech, were obtained for the five word vocab- ulary using the proposed recognition algorithm.

In ${ }^{[5]} \mathrm{A}$ low cost and flexible home control and monitoring system using an embedded micro-web server, with IP connectivity for accessing and controlling devices and appliances remotely using Android based Smart phone app. The proposed system does not require a dedicated server PC with respect to similar systems and offers a novel communication protocol to monitor and control the home environment with more than just the switching functionality. To demonstrate the feasibility and effectiveness of this system, devices such as light switches, power plug, temperature sensor and current sensor have been integrated with the proposed home control system. Building IoTs has advanced significantly in the last couple of years since it has added a new dimension to the world of information and communication technologies . designed and implemented a novel, standalone, flexible and low cost home controlling and monitoring system using RESTful based Web services as an interoperable application layer.

$\ln ^{[6]}$ an increase in the number of accidents and various other traffic related issues. Intelligent Transportation System (ITS) provides the solution to most of these problems by integrating existing technologies with the underlying infrastructure. With the advent of mobile technology and the ubiquitous cellular network, real time vehicle tracking for efficient transport management has become viable. The futile long wait for a bus to arrive can be avoided by Intelligent Public Transportation System. The omnipresence of Smart Phones and their ever increasing power at a very economical price makes them one of the most attractive options for developing IOT applications

In ${ }^{[7]}$ The proliferation of technology paves way to new kind of devices that can communicate with other devices to produce output mostly on wireless communication. Wirelessly communicating embedded devices are brought to one another in a single link over Internet called IoT (Internet of Things). If all objects and people in daily life were equipped with identifiers, computers could manage and inventory them. Besides using RFID, the tagging of things may be achieved through such technologies as near field communication, barcodes, QR codes and digital watermarking. Here new method of using embedded technology to provide such application, Arduino is used as an embedded controller to interface Ethernet shield with a PC/Laptop to provide IoT over Ethernet

In ${ }^{[8]}$ The real-time information services make the public transit system more user-friendly improving the quality and availability of information, supporting needs of passengers in single and multi-modal journeys. As part of a public transport arrival notification system currently ongoing in Severodonetsk, Ukraine, an experimental study has been conducted on forecasting the arrival time of the trolleybuses. This paper discusses the process of developing arrival time estimation algorithms, including remote access configuration, GPS data acquisition, route assigning, algorithm formulation, data processing and calculation of the predicted arrival time.

In ${ }^{[9]}$ Rapid and wide dispersal of passengers after flights makes investigation of flight-related outbreaks challenging. An outbreak of Salmonella Heidelberg was identified in a group of Irish travelers returning from Tanzania. Additional international cases sharing the same flight were identified. Our aim was to determine the source and potential vehicles of infection. Case-finding utilized information exchange using experts' communication networks and national surveillance systems. Demographic, clinical and food history information was collected. Twenty-five additional cases were identified from Ireland, The Netherlands, Norway, USA and Canada.

$\mathrm{In}^{[10]} \mathrm{It}$ is important for every school to have a trustworthy and secure transportation service to ensure the safety of the students. It helps the school administration to effectively manage their bus fleet and potentially reduce mishaps. This is where vehicle monitoring takes effect. The proposed system provides real time information about various parameters of the vehicle like the location, the route, the speed, the list of passengers, the adherence of drivers to schedule and much more. The system further allows the parents to be notified when their ward alights or boards the bus. In this system, we make use of RFID and GPS technologies and connect them to a remote server over WiFiusinganESP8266microcontroller. AnUblox6MGPS module is used to find the current geographic coordinates of the vehicle's location as well as the speed it is going at. AnMFRC522 RFID reader identifies each student as they board or alight the vehicle by reading the id from their RFID tags.

$\operatorname{In}^{[11]}$ Based on the characteristics of the Internet of Things technology, such as sense, transmission, Intelligence, and application, the idea of building a IOT system for the prevention and prewarning of large passenger flows in rail transit was proposed. This paper establishes a network passenger flow distribution model based on the improved logit model, which realizes accurate judgment and intelligent analysis of large passenger flow in rail transit, and uses passenger flow model data to automatically and intelligently display track events and risk prediction and intelligent pre-warning capabilities. Based on the Internet of Things technology, this paper builds a rail transit passenger flow prevention and pre-warning IOT system with rail operation, supervision and service.

In ${ }^{[12]}$ It is clear that the flight catering industry is changing very rapidly, and hence the role of the chef is changing too. According to some reports, the level of food production conducted in flight kitchens has declined to less than 10 per cent of total activity in many units. At the same time the food production that remains has become even more complex and sophisticated. This movement towards a logistics-driven business has required dichotomous work in the catering units: de-skilled and en-skilled/reskilled. The trend towards operations based largely on modern cooking technologies and greater use of buy-in ready-to-use products results in de-skilling. 
$\mathrm{In}^{[13]}$ The researchers administered a 20-question food safety survey to catering employees and observed their actions while performing catering duties. The purpose of this paper is to analyze the food safety knowledge and practices of catering employees in one city in the Southwestern United States. The paper finds that employees earned a mean score of 71.5 per cent on the 20-question survey. They were most knowledgeable about personal hygiene, but did not practice proper hygiene during the catering functions. The most common food safety violations were not wearing gloves when required, not washing hands, not checking food temperatures, and not properly covering foods in warming and/or refrigeration units. Lack of interest and concern about bad publicity prevented many caterers from participating in the study. The presence of observers during a catering event could have affected employees' performance. The results showed need for improvement in both knowledge and practice of food safety and sanitation and significant differences in knowledge between English- and Spanish-speaking respondents and employees of independent versus corporate operations. The paper reveals that the US Food and Drug Administration has a goal of reducing the five risk factors of food-borne illness by 25 percent by 2010 . Catering operations face great challenges in minimizing these risks.

$\ln { }^{[14]}$ DSR provides particular benefits for applications for

mobile devices such as improved recognition performance compared to using the voice channel and ubiquitous access from different networks with a guaranteed level of recognition performance. Because it uses the data channel, DSR facilitates the creation of an exciting new set of applications combining voice and data. To enable all these benefits in a wide market containing a variety of players including terminal manufactures, operators, server providers and recognition vendors, a standard for the front-end is needed to ensure compatibility between the terminal and the remote recognizer. The STQ-Aurora DSR Working Group within ETSI has been actively developing this standard and as a result of this work the first DSR standard was published by ETSI in February 2000. This paper presents an overview of the standard for the DSR Mel-Cepstrum front-end and compression algorithm together with its performance characteristics.

$\mathrm{In}^{[15]}$ With the broadest sample to date among similar studies, namely 37,000 passengers surveyed at 8 different airports with 38 explanatory variables, a large number of conclusions have been drawn. The most important of these is that the factors that most influence a passenger's using a catering establishment during his/her stay at an airport are his/her physiological needs and social reasons. However, contrary to what was anticipated a priori, socioeconomic status only has a moderate influence, while having a wide range and variety of foodstuffs on offer does not result in passengers consuming more. It is also observed that low-cost airline passengers consume less than those of traditional airlines, probably due to the stress related to boarding with these types of airlines. This study identifies the supply and catering sectors, and particularly the smaller companies in those sectors, as the least systematic when developing new product and services.

\section{DESIGN METHODOLOGY}

A. System Flowchart

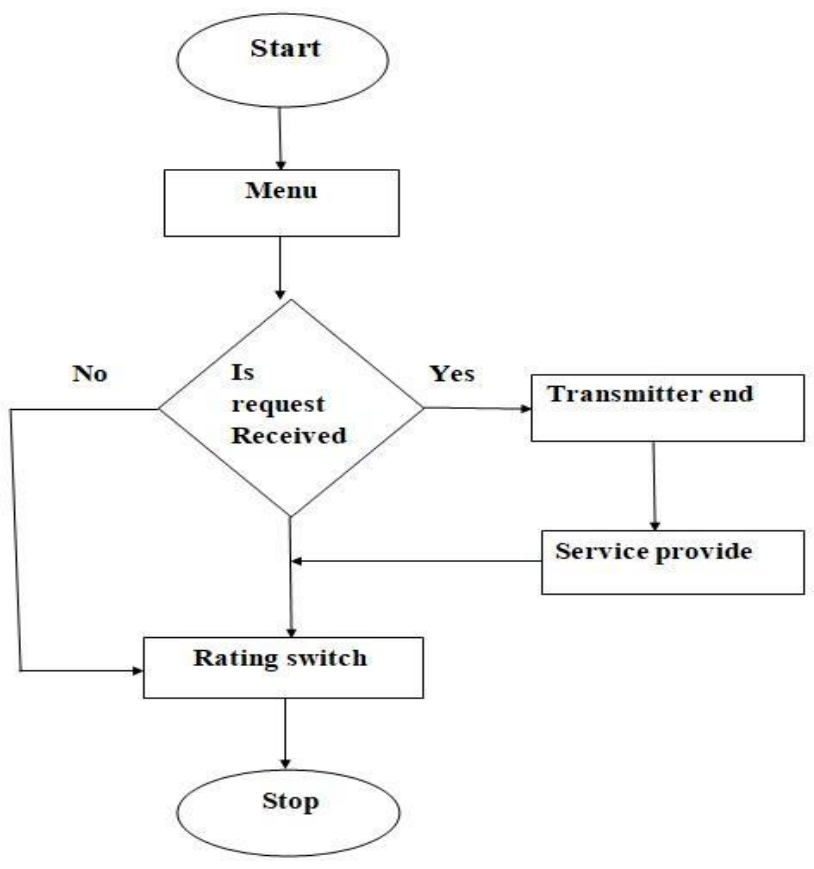


Vol. 8, Issue 4, April 2019

It is a diagram of the sequence of movements or actions of people or things involved in a complex system or activity. The working of this flow diagram is initially start with the menu button in front of the seat .This system consist of display. The display consist the menu buttons. Its works with users need. The requested services will be transmitted to the receiver end as per the needs. This process will done immediately within a span of time. If there is no request the system will be in sleep mode.

B. Block Diagram
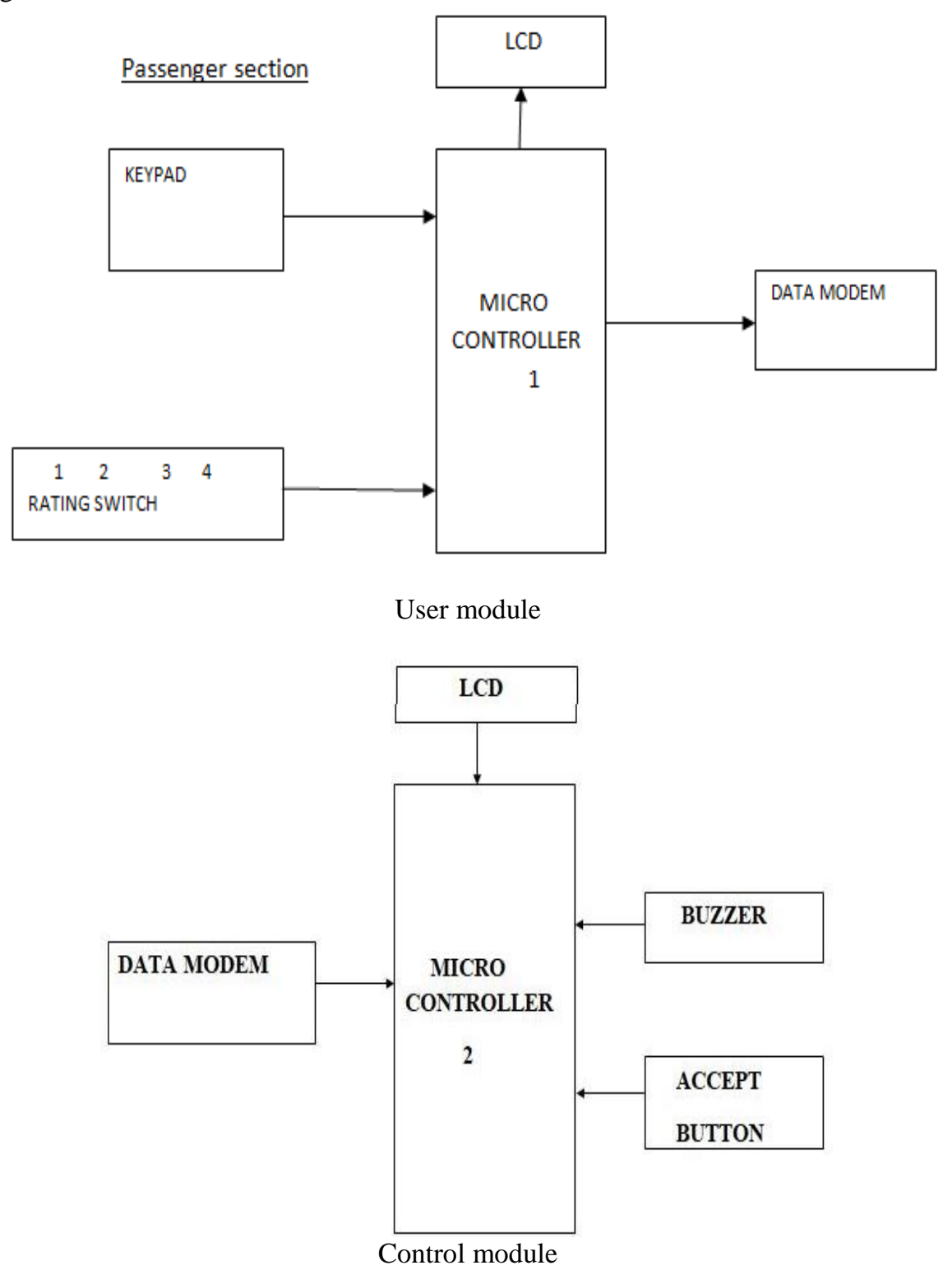

The proposing system is an embedded system. The project section consist of two section. one is passenger section and other is control room section. In the passenger section, they can request there needs by pressing a button and spoke to the speech recognition system in front of the person .the request speech is send to the control room section and it is displayed on an lcd. The request needs may be food, water and if it is "any other helps". The servicer directly goes to the requested person.

The embedded system consist of ATMEGA 328 microcontroller, which is a 32 bit microcontroller. An LCD, RF modem, keypad and a rating switch is attached with it. The two sections are connected with a data modem. If the passenger needs a service he/she can select from the display by pressing the button. It contains a micro controller Atmega 328. By the help of the modem it can transmit to the control room section. Here it contains two micro controllers in two sections. the input from the first micro controller will transmit to the next micro controller using the data modem. When the requirement is received at the control room section there will be have a notification. So the service provider can know the need of the ordered things. The service will be done immediately within a time. This helps the passengers to meet their requirement fastly. 


\section{SYSTEM OVERVIEW}

The passenger service system is an embedded system The project section consist of two section. one is passenger section and other is control room section. In the passenger section, they can request there needs by pressing a button and spoke to the speech recognition system in front of the person .the request speech is send to the control room section and it is displayed on an lcd. The request needs may be food, water and if it is "any other helps". The servicer directly goes to the requested person.

A. Micro-controller

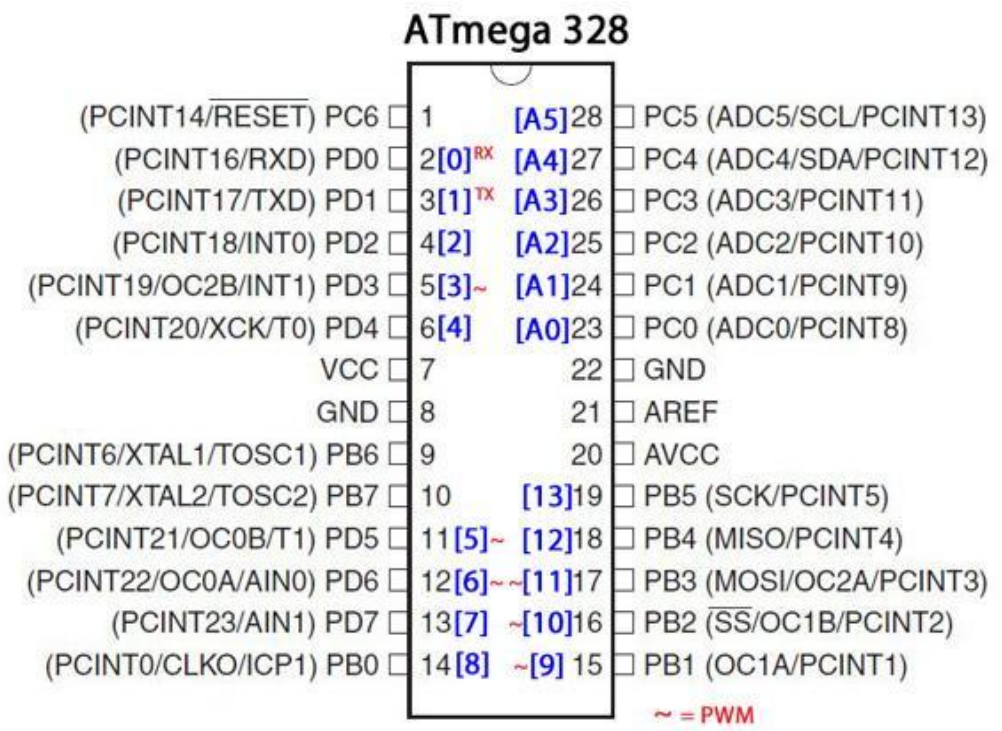

The microcontroller used here is ATmega 328 which is provided with 28 pins. TheATmega328 is a low-power CMOS 8-bit microcontroller based on the AVR enhanced RISC architecture. By executing powerful instructions in a single clock cycle, the ATmega328 achieves throughputs close to 1MIPS per MHz. This empowers system designer to optimize the device for power consumption versus processing speed. Microcontroller is programmed with a threshold value of water level and comparing it with the value given by the float sensor.

\section{B.DATA MODEM}

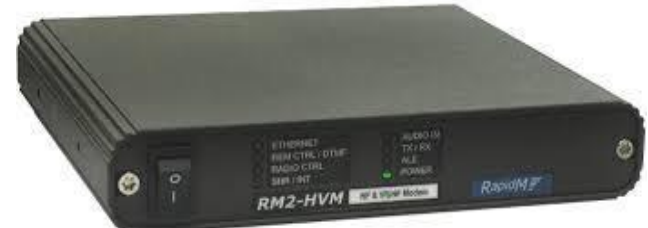

Radio modems encode, transmit, receive and decode serial data using radio waves. They connect to serial ports on devices such as video cameras and data acquisition systems, and send signals to and receive signals from other radio modems.

\section{RESULTS}

This test is to determine the average time it takes. Quick response is the primary points of the efficiency of the design prototype.

\section{CONCLUSION}

Our system is trying to avoid the problems created during the service time. The problem that the passengers facing the time taken to complete their requirements. Many people were isolated in different location and the receiver end because of their heavy duty.. Here comes the need of our project idea. By keeping our product in the transportation media, we can easily send the location to the receiver end. The RF modem is used to communicate between the receiver end and transmitter end. The implementation of the project controls the time delay between the services. 
Vol. 8, Issue 4, April 2019

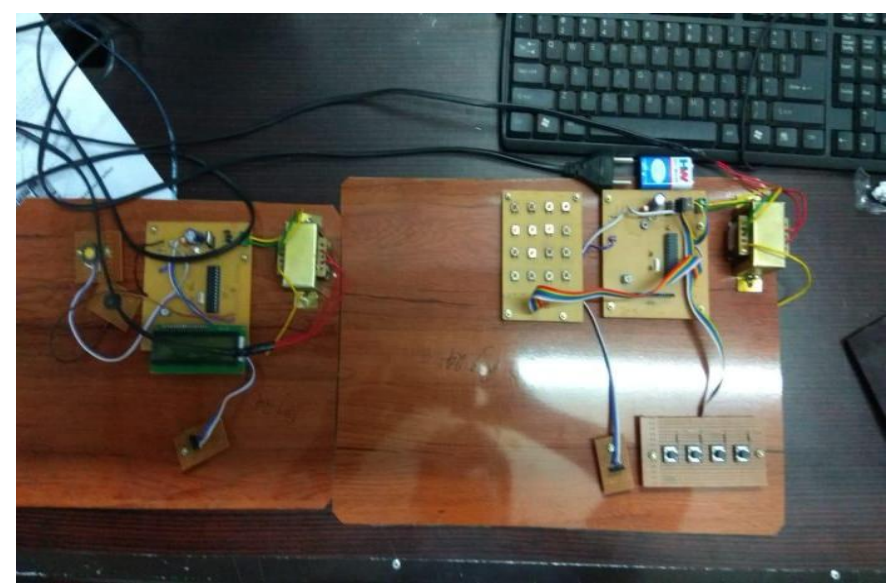

REFERENCES

[1]. IoT Based System for Passenger Service In Railways With Secure ICN architecture. Proceedings of the 2nd International Conference on Trends in Electronics and Informatics (ICOEI 2018) IEEE Conference Record: \# 42666; IEEE Xplore ISBN:978-1-5386-3570-4

[2]. Advanced Train Reservation And Passenger Intimation With Safety System ICICES2014 - S.A. Engineering College, Chennai, Tamil Nadu, India

[3]. IoT Based Airport Parking System IEEE Sponsored 2nd International Conference on Innovations in Information Embedded and Communication Systems ICIIECS'15

[4]. Automatic Recognition of Keywords in Unconstrained Speech Using Hidden Markov Models . IEEE TRANSACTIONS ON ACOUSTICS. SPF.kCH. AND SIGNAL PROCESSING. VOL. 3X. NO. II. NOVEMBER 1990

[5]. Internet of Things: Ubiquitous Home Control and Monitoring System using Android based Smart Phone Rajeev Piyare Department of Information Electronics Engineering, Mokpo National University, Mokpo, 534-729, Korea South: Liu Xiaosheng and Chen Youliang, "Research of Geographic Information System of Flood Prevention and Control in Poyang Lake Area," The CHINA Association for Science and Technology, vol. 1, Nov. 2004, pp. 462-466.

[6]. Integration of Smart Phone and IOT for development of Smart Public Transportation System2016 International Conference on Internet of Things and Applications (IOTA) Maharashtra Institute of Technology, Pune, India 22 Jan - 24 Jan, 2016

[7]. Petri Net Modeling of Information Flow in the Online Train Ticket Booking System] Proceeding of the IEEE International Conference on Automation and Logistics Zhengzhou, China, August 2012

[8]. The Information Service for Delivering Arrival Public Transport Prediction The 4th IEEE International Symposium on Wireless Systems within the International Conferences on Intelligent Data Acquisition and Advanced Computing Systems 20-21 September, 2018, Lviv, Ukraine

[9]. International outbreak investigation of Salmonella Heidelberg associated with in-flight catering. Epidemiol. Infect. (2014), 142, 833-842. (C) Cambridge University Press 2013 doi:10.1017/S0950268813001714

[10]. IoT Based Smart School Bus Monitoring and Notification System. 2017 IEEE Region 10 Humanitarian Technology Conference (R10-HTC) 21 - 23 Dec 2017, Dhaka, Bangladesh

[11]. Design and Application of Large Passenger Flow Warning System for Urban Rail Transit . 2018 IEEE 3rd Advanced Information Technology, Electronic and Automation Control Conference(IAEAC 2018)

[12]. The role of the chef in flight catering Peter Jones Received (in revised form): 4th November, 2004CHIPR, School of Management Studies for the Service Sector, University of Surrey, Guildford GU2 5XH, UK Tel: +44(0)1483 876377; Fax: +44(0)1483 876301;

[13]. An assessment of food safety knowledge and practices of catering employees Jean Hertzman and Deborah Barrash University of Nevada Las Vegas, Las Vegas, Nevada, USA

[14]. Enabling New Speech Driven Services for Mobile Devices:An overview of the ETSI standards activities for Distributed Speech Recognition Front-ends

[15]. Analysing passenger behaviour towards the catering industry: Implications for airport management Author links open overlay panelJosé I.Castillo-Manzano Lourdes López-Valpuesta 